\title{
Effect of Salvia miltiorrhiza aerial parts on growth performance, nutrient digestibility, and digestive enzymes in rabbits
}

\author{
Jiajia Wang ${ }^{1}$, Yiran Luo ${ }^{1}$, Pei Li ${ }^{1}$, Feike Zhang ${ }^{2}$, and Ning Liu ${ }^{1}$ «*
}

\section{* Corresponding Author: Ning Liu \\ Tel: +86-379-6428-2341: \\ Fax: +86-379-6428-2341 \\ E-mail: ningliu68@163.com}

1 Department of Animal Science, Henan University of Science and Technology, Luoyang 471023, China

${ }^{2}$ Luoyang Xintai Agro-pastoral Technology

Co., Ltd, Luoyang 471400, China

ORCID

Jiajia Wang

https://orcid.org/0000-0002-0324-1817

Yiran Luo

https://orcid.org/0000-0003-0937-8387

Pei Li

https://orcid.org/0000-0001-9866-3061

Feike Zhang

https://orcid.org/0000-0001-8233-6082

Ning Liu

https://orcid.org/0000-0003-1134-0839

Submitted Feb 16, 2021; Revised Apr 14, 2021 ; Accepted May 11, 2021
Objective: This study aimed to investigate the effect of Salvia miltiorrhiza (S.m.) aerial parts as an alternative ingredient on growth performance, nutrient digestibility, and digestive enzymes in growing rabbits.

Methods: Treatments included five tested diets: a control (basal diet), antibiotic (basal diet +enramycin at $5 \mathrm{mg} / \mathrm{kg}$ ), and S.m. aerial parts powder added at 3.0\%, $6.0 \%$, and $9.0 \%$ of feed using 300 growing rabbits.

Results: The diets with S.m. aerial parts addition at 9.0\% decreased $(\mathrm{p}<0.05)$ feed/gain compared to the control, but there were no differences in feed intake and body weight gain. In contrast with the control, the addition of antibiotic increased $(\mathrm{p}<0.05)$ digestibility of dry matter, crude protein, energy, fiber, and ash. The herb addition did not cause differences in the digestibility of most nutrients compared to the antibiotic, but fiber digestibility of the herb at $6.0 \%$ and $9.0 \%$ was lower $(p<0.05)$ than that of the antibiotic. Moreover, the antibiotic and the herb also similarly increased $(\mathrm{p}<0.05)$ the activities of duodenal $\alpha$-amylase, maltase, lipase, and trypsin, compared to the control, and the herb at $6.0 \%$ and $9.0 \%$ showed a greater $(\mathrm{p}<0.05)$ activity of elastase than the dose $3.0 \%$.

Conclusion: The obtained data indicate that S.m. aerial parts can be a potential forage in rabbit's diet at $9.0 \%$ with a beneficial regulation on nutrition and digestion.

Keywords: Digestive Enzyme; Growth Performance; Nutrient Digestibility; Rabbit; Salvia miltiorrhiza Aerial Parts

\section{INTRODUCTION}

Salvia miltiorrhiza (S.m.) is a perennial herbaceous medicinal plant 30 to $80 \mathrm{~cm}$ in height. Recently, clinical studies have confirmed that S.m. crude extract or active components had the ability to treat diabetic, cardiovascular, and neurodegenerative diseases [1-3]. The action mechanism of S.m. relies on the amelioration of oxidative stress by regulating antioxidant systems, such as superoxide dismutase, catalase, and glutathione [4]. The popularity of S.m. phytochemicals lead to a strong market demand and consequent large artificial planted area for obtaining its root while aerial parts including stems, leaves, and flowers are also worthy of investigation.

The significant pharmacological components extracted from S.m. can be mainly divided into two categories: fat-soluble tanshinone compounds and water-soluble salvianolic acids which are representative active ingredients in herbal medicine [5,6]. Given the function against oxidation, inflammation, allergy, and cancer and regulation of tissue repair and regeneration, whether the aerial parts of S.m. can be a forage with a growth-promoting effect in farm animals is unclear. Moreover, no literature reports the relationship between S.m., nutrient digestibility, and digestive enzyme activity.

Therefore, for the exploration of new forage resources and maximum utilization of by- 
products from the human consumption, the present study aimed to investigate the effect of S.m. aerial parts as an alternative ingredient on growth performance, nutrient digestibility, and activities of digestive enzymes in farm rabbits compared to controls with/without a growth-promoting antibiotic.

\section{MATERIALS AND METHODS}

\section{Animal care}

The experimental protocol of the present study was approved by the Institutional Committee for Animal Use and Ethics of Henan University of Science and Technology (No. 2018010).

\section{Salvia miltiorrhiza and diets}

The S.m. was planted in Funiu mountains in Luoyang of China $\left(112^{\circ} 17^{\prime} \mathrm{N}, 34^{\circ} 52^{\prime} \mathrm{E}\right)$ and aerial parts were harvested during the last week of flowering, air dried, ground into meal (40-mesh sieve) and added at 3.0\%, 6.0\%, and 9.0\% in diets [7]. The chemical composition of aerial parts of S.m. was listed in Table 1.

The nutrition levels of diets and animal management were referred to Technical Specification for Feeding and Management of Hyla Rabbits (Table 2). All diets were considered as isoenergetic and isonitrogenic and were fed as cold formed pellets (diameter $\times$ length, $3.5 \times 8.0 \mathrm{~mm}$ ) with water content under $14 \%$ [8].

\section{Animals and samples}

A total of 300 weaned male Hyla rabbits at approximately 35 days old with initial body weight $1,062 \mathrm{~g} \pm 17.8$ (mean \pm standard deviation) were randomly assigned to 5 groups with 6 replicates of 10 rabbits each. Rabbits per replicate were housed individually in a continuous row cage $[9,10]$ and all replicates were uniformly distributed in the rabbit house to minimize spatial errors. The rabbits had free access to the diet and water and free of medication other than experimental factors. The feeding trial lasted for $28 \mathrm{~d}$ after an adjustment period of $5 \mathrm{~d}$. Rabbits and feed in each replicate were weighed weekly. Aver-

Table 1. Chemical compositions of Salvia miltiorrhiza aerial parts (\% of dry matter)

\begin{tabular}{lcc}
\hline Composition & Content & SD \\
\hline Dry matter & 87.1 & 2.296 \\
Crude protein & 11.7 & 0.208 \\
NDF & 60.2 & 2.023 \\
ADF & 41.3 & 1.762 \\
Ca & 0.14 & 0.005 \\
P & 0.19 & 0.005 \\
Ash & 6.92 & 0.174 \\
Tanshinones & 0.63 & 0.021 \\
Salvianolic acids & 0.74 & 0.031 \\
\hline
\end{tabular}

SD, standard deviation; ADF, acid detergent fiber; NDF neutral detergent fiber. age daily feed intake (ADFI), average daily body weight gain (ADG), and feed/gain were immediately adjusted when mortality occurred. All rabbits were monitored for general health twice a day throughout the trial.

At 26 to $28 \mathrm{~d}$ of the feeding trial, fresh feces from individual rabbits were collected, pooled by replicate, and prepared for the analysis of nutrient digestibility [11]. Care was taken during the collection of fecal samples to avoid contamination from fur and other foreign materials. At $28 \mathrm{~d}, 5$ rabbits per replicate were randomly selected, suffocated by carbon dioxide, and then the duodenum were dissected and cleaned with phosphate-buffered saline $\left(0^{\circ} \mathrm{C}\right.$ to $\left.4^{\circ} \mathrm{C}\right)$ and mucosa samples were collected and stored at $-40^{\circ} \mathrm{C}$ for digestive enzyme assay [12].

\section{Chemical and biochemical analysis}

Chemical analysis of proximate nutrients in diets and S.m. aerial parts was carried out according to the method by Liu et al [11]. Total tanshinone compounds and phenolic acids in S.m. were detected according to Pharmacopoeia of China (Volume I, 2015) by high performance liquid chromatography and thin layer chromatography, respectively.

Assay kits from Nanjing Jiancheng Biological Institute (Nanjing, China) were used for the detection of lipase (A0541-1), $\alpha$-amylase (C016-2-1), sucrase (A082-2-1), maltase (A082-3-1), trypsin (A080-2-2), and elastase (H198). All samples were carried out in triplicate according to the specifications of kits. The units of enzymes were finally calculated and expressed as per mg of protein in the supernatant of tissue samples to minimize the errors during sample preparation.

Table 2. Ingredients and nutrient levels of basal diet and diets containing Salvia miltiorrhiza aerial parts

\begin{tabular}{|c|c|c|c|c|}
\hline \multirow{2}{*}{$\begin{array}{l}\text { Item } \\
\text { Ingredient (\% as fed) }\end{array}$} & \multirow[t]{2}{*}{ Basal diet } & \multicolumn{3}{|c|}{ Aerial parts } \\
\hline & & & & \\
\hline Aerial parts & 0 & 3.0 & 6.0 & 9.0 \\
\hline Alfalfa meal & 35.0 & 32.0 & 31.0 & 31.0 \\
\hline Corn & 25.0 & 25.0 & 25.0 & 25.0 \\
\hline Soybean meal & 10.0 & 10.0 & 10.0 & 11.0 \\
\hline Brewers dried grain & 15.0 & 15.0 & 13.0 & 11.0 \\
\hline Wheat bran & 10.0 & 10.0 & 10.0 & 8.0 \\
\hline Premix ${ }^{1)}$ & 5.0 & 5.0 & 5.0 & 5.0 \\
\hline \multicolumn{5}{|l|}{ Nutrients ${ }^{2)}$ (\% of dry matter) } \\
\hline Crude protein & 16.5 & 16.4 & 16.1 & 16.2 \\
\hline Digestible energy (MJ/kg) & 10.53 & 10.52 & 10.46 & 10.37 \\
\hline Acid detergent fiber & 15.7 & 16.1 & 16.3 & 16.8 \\
\hline Neutral detergent fiber & 23.4 & 24.0 & 24.2 & 24.7 \\
\hline Ash & 6.61 & 6.57 & 6.63 & 6.58 \\
\hline \multicolumn{5}{|c|}{$\begin{array}{l}\text { 1) The premix provided the following per kg of the diet: vit A, } 6,000 \mathrm{IU} \text {; vit D } \\
1,000 \mathrm{IU} ; \text { vit E, } 38 \mathrm{mg} ; \mathrm{Cu}, 9 \mathrm{mg} ; \mathrm{Fe}, 50 \mathrm{mg} ; \mathrm{Mn}, 9.0 \mathrm{mg} ; \mathrm{Zn}, 40 \mathrm{mg} \text {; dicalci } \\
\text { um phosphate, } 25 \mathrm{~g} \text {; NaCl, } 4.0 \mathrm{~g} \text {; Lys, } 2.4 \mathrm{~g} ; \mathrm{Met}, 1.6 \mathrm{~g} \text {. } \\
\text { 2) Digestible energy was calculated by Chinese Feed Database (version } \\
\text { 28, 2017) and others were measured. }\end{array}$} \\
\hline
\end{tabular}




\section{Statistics}

Data were subjected to analysis of variance and means $(\mathrm{n}=$ 6) were separated by Tukey's-b test at $p<0.05$ using IBM SPSS (version 23). Statistical unit for growth performance and nutrient digestibility was from the average of 10 rabbits per replicate and intestinal digestive enzymes from 5 anatomic rabbits.

\section{RESULTS}

Salvia miltiorrhiza and growth performance

Mortality of rabbits throughout the experiment was $<5 \%$, not statistically significant among treatments (data not shown). The diets supplemented with S.m. aerial parts at 3.0\%, 6.0\%, and $9.0 \%$ had no significant effects on ADFI and ADG (Table $3)$, while the dose at $9.0 \%$ decreased $(\mathrm{p}<0.05)$ feed/gain by
$6.2 \%$ compared to the control, but there were no differences among other treatments.

\section{Salvia miltiorrhiza and nutrient digestibility}

The antibiotic addition increased $(\mathrm{p}<0.05)$ the digestibility of dry matter, crude protein, energy, ADF, NDF, and minerals, compared to the control (Table 4). For S.m. aerial parts, similar results were found with these nutrients except for ADF and NDF which were lower $(\mathrm{p}<0.05)$ than the antibiotic but similar to the control.

\section{Salvia miltiorrhiza and digestive enzymes}

Significant treatment effects $(\mathrm{p}<0.05)$ were found with the activity of a-amylase, maltase, lipase, trypsin, and elastase, except for sucrose (Table 5). Antibiotic supplementation resulted in a higher $(\mathrm{p}<0.05)$ enzyme activity than the control

Table 3. Effect of Salvia miltiorrhiza aerial parts on the growth performance of rabbits

\begin{tabular}{|c|c|c|c|c|c|c|c|}
\hline \multirow{2}{*}{ Item } & \multirow{2}{*}{ Control } & \multirow{2}{*}{ Antibiotic } & \multicolumn{3}{|c|}{ Supplemental aerial parts } & \multirow{2}{*}{ SEM } & \multirow{2}{*}{ p-value } \\
\hline & & & $3.0 \%$ & $6.0 \%$ & $9.0 \%$ & & \\
\hline Initial BW (kg/rabbit) & 1.07 & 1.06 & 1.07 & 1.05 & 1.06 & 0.049 & 0.998 \\
\hline Final BW (kg/rabbit) & 2.65 & 2.74 & 2.66 & 2.68 & 2.60 & 0.057 & 0.188 \\
\hline ADFI (g/rabbit/d) & 164 & 167 & 159 & 160 & 150 & 7.786 & 0.283 \\
\hline ADG (g/rabbit/d) & 56.4 & 60.3 & 56.8 & 58.2 & 55.3 & 1.633 & 0.056 \\
\hline Feed/gain $(\mathrm{g} / \mathrm{g})$ & $2.91^{\mathrm{a}}$ & $2.77^{\mathrm{ab}}$ & $2.80^{\mathrm{ab}}$ & $2.75^{\mathrm{ab}}$ & $2.73^{b}$ & 0.082 & 0.049 \\
\hline
\end{tabular}

SEM, standard error of mean; BW, body weight; $A D F I$, average daily feed intake; $A D G$, average daily $B W$ gain

$a, b$ Means in a row without the same superscript are different, $p<0.05$.

Table 4. Effect of Salvia miltiorrhiza aerial parts on the nutrient digestibility of rabbits

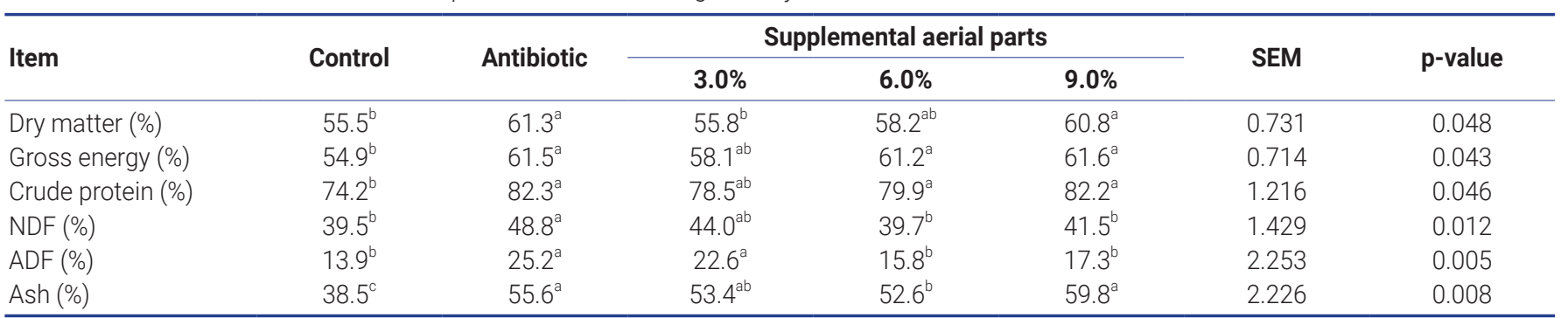

SEM, standard error of mean; NDF neutral detergent fiber; ADF, acid detergent fiber.

${ }^{a-c}$ Means in a row without the same superscript are different, $p<0.05$.

Table 5. Effect of Salvia miltiorrhiza aerial parts on the duodenal digestive enzymes of rabbits

\begin{tabular}{|c|c|c|c|c|c|c|c|}
\hline \multirow{2}{*}{ Item } & \multirow{2}{*}{ Control } & \multirow{2}{*}{ Antibiotic } & \multicolumn{3}{|c|}{ Supplemental aerial parts } & \multirow{2}{*}{ SEM } & \multirow{2}{*}{ p-value } \\
\hline & & & $3.0 \%$ & $6.0 \%$ & $9.0 \%$ & & \\
\hline a-Amylase (U/mg) & $14.0^{b}$ & $19.8^{\mathrm{a}}$ & $17.2^{\mathrm{ab}}$ & $20.1^{a}$ & $19.9^{\mathrm{a}}$ & 0.535 & 0.038 \\
\hline Sucrase (U/mg) & 1.68 & 1.57 & 1.58 & 1.69 & 1.61 & 0.058 & 0.872 \\
\hline Maltase (U/mg) & $2.15^{\mathrm{b}}$ & $2.47^{\mathrm{a}}$ & $2.34^{\mathrm{ab}}$ & $2.39^{\mathrm{ab}}$ & $2.52^{\mathrm{a}}$ & 0.066 & 0.046 \\
\hline Lipase (U/g) & $1.59^{b}$ & $1.72^{\mathrm{a}}$ & $1.65^{\mathrm{ab}}$ & $1.70^{\mathrm{a}}$ & $1.73^{\mathrm{a}}$ & 0.034 & 0.048 \\
\hline Trypsin (U/mg) & $3.17^{b}$ & $3.59^{\mathrm{a}}$ & $3.21^{\mathrm{ab}}$ & $3.53^{a}$ & $3.65^{\mathrm{a}}$ & 0.074 & 0.046 \\
\hline Elastase $(\mathrm{U} / \mathrm{mg})$ & $0.25^{\mathrm{a}}$ & $0.28^{\mathrm{a}}$ & $0.20^{b}$ & $0.27^{a}$ & $0.28^{a}$ & 0.011 & 0.032 \\
\hline
\end{tabular}

SEM, standard error of mean.

${ }_{a, b}$ Means in a row without the same superscript are different, $p<0.05$. 
group for $\alpha$-amylase, maltase, lipase, and trypsin. The herb at the three doses and the antibiotic had similar effects on these enzymes, but there were no significant dose effects. For elastase, the antibiotic, and the herb at $6.0 \%$ and $9.0 \%$ did not increase its activity, and the dose $3.0 \%$ exhibited the lowest $(\mathrm{p}<0.05)$ activity.

\section{DISCUSSION}

Root plants including S.m. are well-known for their root utilization but more than half of photosynthesis products are deposited in aerial leaves and stems which can be a good forage source for herbivores [13]. Especially under artificial planting, aerial parts of root crops have a high yield [5]. In the present study, mowing of S.m. was arranged at the last week of the flowering period that lasts approximate 6 months, thereby leading to less lignification, higher nutritional values reflecting on crude fiber and crude protein and a non-significant negative effect on root growth and quality (data not shown) from the serial pilot studies of authors. The proximate nutrient contents primarily indicate that S.m. aerial parts can be a forage in the rabbit feed.

The S.m. aerial parts at the three doses did not cause differences in ADFI and ADG of rabbits among treatments. Literature showed that tanshinone IIA increased ADG of broilers with pulmonary arterial hypertension [14]; Salvia root improved egg performance of hens [15]; however, salvianolic acid B prevented ADG in high-fat diet-induced obese mice [16]. These inconsistencies in feed consumption and growth by feeding aerial parts, root, or bioactive compounds of S.m. to animals need further studies. Interestingly, the feed efficiency in the herb at $9.0 \%$ was greater, demonstrating its beneficially physiological regulation. This may be due to the bioactive components of S.m. because tanshinones and salvianolic acids are capable against oxidative stress and inflammation $[3,17]$. Furthermore, the comparable ADG between the herb and the antibiotic implies the potential growth-promoting effect of S.m. aerial parts.

In the present study, in contrast with the control, supplementation of the antibiotic and the herb resulted in significant increases in the digestibility of nutrients of rabbits. The improved feed efficiency and nutrient digestibility may also be attributed to health benefits of tanshinones and salvianolic acids of S.m. Indeed, S.m. root improved intestinal barrier integrity, physiological metabolism, and amino acids absorption $[18,19]$. Paradoxically, in a rodent model, tanshinones and salvianolic acids depressed nutrient deposition and modulated gut microbiota $[16,20]$. Information is however unavailable about the effect of S.m. aerial parts on the growth performance and nutrient digestion in farm animals. In the present study, significant increases in nutrient digestibility of diets with the herb addition indicate its beneficial regulation on the digestive physiology of rabbits.

Indeed, the activities of digestive enzymes including a-amylase, sucrase, maltase, lipase, and trypsin were increased in diets containing S.m. aerial parts. However, high doses of flavonoids from Salvia chlorolueca aerial parts showed inhibitory effects on $\alpha$-amylase and $\alpha$-glucosidase [21]. Similarly, cryptotanshinone or tanshinone IIA from S.m. at 1\% inhibited pancreatic lipase activity [22]. Jordan indigenous Salvia spp. extracts depressed gastrointestinal carbohydrate and lipid digestion and absorption [23]. Besides the flavonoid concentration, the underlying reason why the extracted flavonoids and their raw materials showed reverse effects on carbohydrases and lipase deserves further study, and molecular docking studies will be needed to establish whether a direct interaction of the principal constituents of the S.m. with digestive enzymes can be evoked. Importantly, the herb also improved protein digestion, but literature is unavailable about S.m. or its extracts on the activity of proteases, which needs further study. Additionally, with increasing threats from the environment and pathogens, intestinal antioxidant activity of farm animals becomes especially important [2427], whether the dietary aerial parts of S.m. influence intestinal health is also an interesting topic.

\section{CONCLUSION}

Supplementation of S.m. aerial parts at the dose $9.0 \%$ decreased feed/gain compared to the control. The antibiotic exhibited significant improvement in the digestibility of dry matter, crude protein, energy, fiber, and ash, and similar results were found for the herb for most nutrients except for fiber which was lower than the antibiotic but similar to the control. The antibiotic and the herb had similar effects on the activities of $\alpha$-amylase, sucrase, maltase, lipase, and trypsin. The results suggest that S.m. aerial parts can be a versatile forage with nutritional and growth-promoting effects on herbivores.

\section{CONFLICT OF INTEREST}

We certify that there is no conflict of interest with any financial organization regarding the material discussed in the manuscript. Liu N is an employee of Luoyang Xintai Agro-pastoral Technology Co., Ltd.

\section{ACKNOWLEDGMENTS}

The authors thank the animal keepers of Luoyang Xintai Agro-pastoral Technology and laboratory staff of the Animal Nutrition Group, Henan University of Science and Technology, and all colleagues and students for support in practical work. 


\section{REFERENCES}

1. Jia Q, Zhu R, Tian Y, et al. Salvia miltiorrhiza in diabetes: A review of its pharmacology, phytochemistry, and safety. Phytomedicine 2019;58:152871. https://doi.org/10.1016/j.phymed. 2019.152871

2. Ren J, Fu L, Nile SH, Zhang J, Kai G. Salvia miltiorrhiza in treating cardiovascular diseases: A review on its pharmacological and clinical applications. Front Pharmacol 2019;10:753. https://doi.org/10.3389/fphar.2019.00753

3. Wu Y, Xu S, Tian XY. The Effect of salvianolic acid on vascular protection and possible mechanisms. Oxid Med Cell Longev 2020;2020:5472096. https://doi.org/10.1155/2020/5472096

4. Jung I, Kim H, Moon S, Lee H, Kim B. Overview of Salvia miltiorrhiza as a potential therapeutic agent for various diseases: an update on efficacy and mechanisms of action. Antioxidants 2020;9:857. https://doi.org/10.3390/antiox 9090857

5. Zeng H, Su S, Xiang X, et al. Comparative analysis of the major chemical constituents in Salvia miltiorrhiza roots, stems, leaves and flowers during different growth periods by UPLC-TQ-MS/MS and HPLC-ELSD methods. Molecules 2017;22:771. https://doi.org/10.3390/molecules22050771

6. Jiang Z, Gao W, Huang L. Tanshinones, critical pharmacological components in Salvia miltiorrhiza. Front Pharmacol 2019;10:202. https://doi.org/10.3389/fphar.2019.00202

7. Wang J, Lin L, Li B, Zhang F, Liu N. Dietary Artemisia vulgaris meal improved growth performance, gut microbes, and immunity of growing Rex rabbits. Czech J Anim Sci 2019;64: 174-9. https://doi.org/10.17221/162/2018-CJAS

8. Ding K, Wang J, Liu N, Zhang F. Effect of Artemisia apiacea Hance on growth performance, cecal opportunistic bacteria, and microbicidal peptides in rabbits. R Bras Zootec 2019;48: e20190118. https://doi.org/10.1590/rbz4820190118

9. Zhao H, Zhang F, Chai J, Wang J. Effect of lactic acid bacteria on Listeria monocytogenes infection and innate immunity in rabbits. Czech J Anim Sci 2020;65:23-30. https://doi.org/10. 17221/247/2019-CJAS

10.Zhao H, Zhang F, Chai J, Wang J. Lactobacillus acidophilus reduces Listeria monocytogenes infection by inhibiting mitogenactivated protein kinase genes in growing rabbits. $\mathrm{R}$ Bras Zootec 2020;49:e20200054. https://doi.org/10.37496/rbz4920 200054

11.Liu N, Wang JQ, Gu KT, Deng Q, Wang JP. Effects of dietary protein levels and multienzyme supplementation on growth performance and markers of gut health of broilers fed a miscellaneous meal based diet. Anim Feed Sci Technol 2017; 234:110-7. https://doi.org/10.1016/j.anifeedsci.2017.09.013

12.Liu N, Wang JQ, Jia S, Chen Y, Wang JP. Effect of yeast cell wall on the growth performance and gut health of broilers challenged with aflatoxin $B_{1}$ and necrotic enteritis. Poult Sci 2018;97:477-84. https://doi.org/10.3382/ps/pex342
13. Abdallah A, Zhang P, Zhong Q, Sun Z. Application of traditional Chinese herbal medicine by-products as dietary feed supplements and antibiotic replacements in animal production. Curr Drug Metab 2019;20:54-64. https://doi.org/10. 2174/1389200219666180523102920

14. Hu G, Song Y, Ke S, et al. Tanshinone IIA protects against pulmonary arterial hypertension in broilers. Poult Sci 2017; 96:1132-8. https://doi.org/10.3382/ps/pew322

15. Yang CW, Ding X, Zhao X, Guo YX, Mu AL, Yang ZB. Effects of star anise (Illicium verum Hook. f.), salvia miltiorrhiza (Salvia miltiorrhiza Bge) and ginger root (Zingiber officinale Roscoe) on laying performance, antioxidant status and egg quality of laying hens. Eur Poult Sci 2017;81:183. https://doi.org/10. 1399/eps.2017.183

16.Li L, Li R, Zhu R, et al. Salvianolic acid B prevents body weight gain and regulates gut microbiota and LPS/TLR4 signaling pathway in high-fat diet-induced obese mice. Food Funct 2020;11:8743-56. https://doi.org/10.1039/d0fo01116a

17. Chen X, Wu R, Kong Y, et al. Tanshinone II aattenuates renal damage in STZ-induced diabetic rats via inhibiting oxidative stress and inflammation. Oncotarget 2017;8:31915-22. https:// doi.org/10.18632/oncotarget.16651

18. Kong XF, Wu GY, Yin YL. Roles of phytochemicals in amino acid nutrition. Front Biosci 2011;3:372-84. https://doi.org/ $10.2741 / \mathrm{s} 157$

19.Wang K, Yang Q, Ma Q, et al. Protective effects of salvianolic acid A against dextran sodium sulfate-induced acute colitis in rats. Nutrients 2018;10:791. https://doi.org/10.3390/nu100 60791

20.Cai H, Su S, Li Y, et al. Danshen can interact with intestinal bacteria from normal and chronic renal failure rats. Biomed Pharmacother 2019;109:1758-71. https://doi.org/10.1016/j. biopha.2018.11.047

21.Asghari B, Salehi P, Sonboli A, Ebrahimi SN. Flavonoids from Salvia chloroleuca with $\alpha$-amylsae and $\alpha$-glucosidase inhibitory effect. Iran J Pharm Res 2015;14:609-15.

22. Marrelli M, Grande F, Occhiuzzi MA, Maione F, Mascolo N, Conforti F. Cryptotanshinone and tanshinone IIA from Salvia milthorrhiza Bunge (Danshen) as a new class of potential pancreatic lipase inhibitors. Nat Prod Res 2021;35:863-6. https://doi.org/10.1080/14786419.2019.1607337

23. Kasabri V, Afifi FU, Abu-Dahab R, et al. In vitro modulation of metabolic syndrome enzymes and proliferation of obesity related-colorectal cancer cell line panel by Salvia species from Jordan. Rev Roum Chim 2014;59:693-705.

24.Liu N, Ding K, Wang JQ, Jia SC, Wang JP, Xu TS. Detoxification, metabolism, and glutathione pathway activity of aflatoxin $\mathrm{B} 1$ by dietary lactic acid bacteria in broiler chickens. J Anim Sci 2017;95:4399-406. https://doi.org/10.2527/jas2017. 1644

25.Liu N, Deng X, Liang C, Cai H. Effect of broccoli residues fermented with probiotics on the growth performance and 
health status of broilers challenged with Clostridium perfringens. Braz J Poult Sci 2018;20:625-32. https://doi.org/10. 1590/1806-9061-2018-0741

26. Wang J, Lin L, Jiang Q, Huang WL, Liu N. Probiotics and clay detoxifier protected growth performance and intestinal barrier of lambs fed diet contaminated with aflatoxin $\mathrm{B}_{1}$. Indian
J Anim Sci 2019;89:658-62.

27. Shi H, Shi H, Li Y, Liu N. Effect of lactic acid bacteria on growth performance, oxidative status and infectious parameters induced by Listeria monocytogenes in broilers. Eur Poult Sci 2020;84:316. https://doi.org/10.1399/eps.2020.316 